\title{
Integration of Basic Sciences in Undergraduate Nursing Curricula
}

\author{
Fred Saleh* \\ Associate Dean and Clinical Director, Director of the Nursing Degree Program, Phoenicia University, Beirut, Lebanon
}

*Corresponding author: Fred Saleh, Director of the Nursing Degree Program, College of Public Health, Phoenicia University, Beirut, Lebanon, Email: fred.saleh@pu.edu.lb.

To Cite This Article: Fred Saleh. Integration of Basic Sciences in Undergraduate Nursing Curricula. Am J Biomed Sci \& Res. 2019 - 4(3). AJBSR. MS.ID.000798. DOI: 10.34297/AJBSR.2019.04.000798

Received: July 17, 2019 | Published: July 30, 2019

\begin{abstract}
Background and aim: Undergraduate nursing curricula often offer basic science courses during the first academic year of the degree program. These include Gross Anatomy, Embryology, Physiology, Pathophysiology, Biochemistry, and Microbiology. They are often given as separate courses, thus lacking horizontal and vertical integration with major nursing courses, such as medical-surgical nursing, critical care nursing, pediatric nursing, maternal nursing, recovery nursing, emergency nursing, operating room nursing, and geriatric nursing. This study aims to survey undergraduate nursing curricula in Lebanon about the integration of basic science courses.
\end{abstract}

Materials and methods: We conducted two separate comprehensive PubMed and Medline searches using the following combined MeSH terms: “Gross Anatomy, Embryology, Physiology, Pathophysiology, Biochemistry, OR Microbiology, AND Nursing, AND Lebanon". In parallel, we reviewed the nursing degree catalogs and the related description of courses of the nursing programs currently offered by various universities in Lebanon about whether basic sciences are integrated into the curriculum.

Results: Our results showed that Anatomy, Embryology, Physiology, Pathophysiology, Biochemistry, and Microbiology are still delivered as separate courses during the first years of the nursing programs which we reviewed. On very few occasions, some of these courses are rather offered during the second or third year. Also, and except for combining Anatomy with Physiology in one course in some of the reviewed programs, proper horizontal integration is still lacking. Embryology is mostly not given as a separate course, but rather either embedded in the Anatomy course or not given at all. Finally, we did not find vertical integration in the 12-degree-programs which we reviewed.

Discussion and conclusion: Proper horizontal and vertical integration of basic sciences in undergraduate nursing curricula in Lebanon is still lacking. This often results in a knowledge gap, as well as in difficulty in correlating "normal" with "abnormal" by the students.

Keywords: Basic sciences; Nursing curriculum; Undergraduate nursing degree programs; Horizontal integration; Vertical integration

\section{Introduction}

Learning is best achieved when knowledge is acquired in a context. Nursing students enrolled in an undergraduate degree in Nursing often learns the "normal" during their first academic year, before they learn about the "abnormal" in their subsequent years. Consequently, two major issues are confronted from an education point of view: Knowledge is not contextual, and there is no integration and correlation between "normal" and "abnormal".

Many nursing students have a difficult time understanding basic science concepts, such as acid-base balance, tidal volume, mesoderm, ectoderm, looping of the heart, neural tube, renin-angiotensin system, gram-positive and negative, etc., as they are commonly taught (that is, using an abstract, lecture method), and they desperately need to understand the concepts as they relate to the disease. Traditionally, students have been expected to make these relations on their own, outside the classroom. However, growing numbers of education theories today are discovering that most students' interest and achievement improve dramatically when they are helped to make connections and relations between new knowledge and experiences they have had, or with other knowledge they have already mastered [1-17]. Students' engagement increases significantly when they are taught why they are learning the concepts and how those concepts can be used outside the classroom [1-17]. Contextualized learning is a verified concept that integrates the most recent research in cognitive science [1-17]. The contextual method identifies that learning is a complex and multifaceted process that extends beyond drill-oriented, stimulus-and-response methodologies. 
Accordingly, learning occurs only when students process new knowledge or information in such a way that it makes sense to them in their own borders of reference (their own experience, memory, and response). The mind naturally pursues meaning in context by searching for relationships that look useful and seem sensible. Accordingly, the contextual learning theory focuses on the multiple aspects of any learning environment, be it a classroom, a laboratory, or a clinical setting. It inspires educators to select and/or enterprise learning environments that integrate several different forms of experience in working toward the desired learning outcomes. In such an environment, students learn meaningful relationships between abstract ideas and practical applications in the context of the real world, whereby concepts are internalized through the process of integrating, reinforcing, discovering, and correlating [1-17]. We aimed in this study to survey undergraduate nursing curricula in Lebanon about the integration of basic science courses.

\section{Materials and Methods}

We conducted two separate comprehensive PubMed and Medline searches using the following combined MeSH terms: "Gross Anatomy, Embryology, Physiology, Pathophysiology, Biochemistry, OR Microbiology, AND Nursing, AND Lebanon". We selected "All Fields" in both searches to ensure that if such MeSH terms are included in the title, abstract, keywords, or any other components of the journal articles searched, then such articles will automatically appear in our search. We did not use any of the filters available in the PubMed and Medline search engines, such as article types, text availability, publication dates, ages, search fields, languages, sex, subjects, and journal categories to avoid accidental exclusion of any articles that match the MeSH terms we used.

In parallel, we reviewed the nursing degree catalogs and the related description of courses of the nursing programs currently offered by the various universities in Lebanon about whether basic sciences are integrated into the curriculum. Access to such catalogs and description of courses was obtained through screening the related degree programs posted on the websites of these universities. These websites were located through Erasmus Plus Lebanon, and through visiting 132 individual website links obtained through Google search for "nursing degree in Lebanon" [18].

\section{Results}

A total of 12 different undergraduate nursing programs from 12 universities in Lebanon were reviewed. Our results showed that Anatomy, Embryology, and Physiology are delivered during the first academic year in $100 \%$ of the programs surveyed (Table 1). They are combined in $75 \%$ of the programs studied, while they are given as separate entities in the remaining $25 \%$ of the programs. With a very exception (17\%), Embryology is not given as a separate course, but rather either embedded in the Anatomy course or not given at all. Pathophysiology is given in 58\% of the surveyed programs, of which $86 \%$ delivered in Year 2, and 14\% in Years 3 and 4 (course labeled as Pathology). Microbiology is given in $75 \%$ of the surveyed programs, of which $89 \%$ in Year 1, and 11\% in Year 3. Biochemistry is delivered in $50 \%$ of the programs, of which $83 \%$ in Year 1 (given as Elective in one program), and $17 \%$ in Year 2.

\begin{tabular}{|c|c|c|c|c|c|c|c|}
\hline \multirow{2}{*}{ University } & \multicolumn{6}{|c|}{ Basic Science Course Offered } & \multirow{2}{*}{ Academic Year } \\
\hline & Anatomy & Embryology & Physiology & Pathophysiology & Microbiology & Biochemistry & \\
\hline \multirow{3}{*}{1} & $\S \sqrt{ }$ & $\partial \sqrt{ }$ & $+\sqrt{ }$ & & $\sqrt{ }$ & $\sqrt{ }$ & *Year I \\
\hline & & & & $\sqrt{ }$ & & & Year 2 \\
\hline & & & & & & & Year 3 \\
\hline \multirow{3}{*}{2} & $\sqrt{ }$ & $\sqrt{ }$ & $\sqrt{ }$ & $\sqrt{ }$ & & & *Year I \\
\hline & & & & & & & Year 2 \\
\hline & & & & & $\sqrt{ }$ & & Year 3 \\
\hline \multirow{3}{*}{3} & $\sqrt{ }$ & $\sqrt{ }$ & $\sqrt{ }$ & $\sqrt{ }$ & $\sqrt{ }$ & & *Year I \\
\hline & & & & & & & Year 2 \\
\hline & & & & & & & Year 3 \\
\hline \multirow{3}{*}{4} & $\S \sqrt{ }$ & $\partial \sqrt{ }$ & $+\sqrt{ }$ & $\sqrt{ }$ & $\sqrt{ }$ & $\sqrt{ }$ & *Year I \\
\hline & & & & & & & Year 2 \\
\hline & & & & & & & Year 3 \\
\hline \multirow{3}{*}{5} & $\S \sqrt{ }$ & $\partial \sqrt{ }$ & $+\sqrt{ }$ & & $\sqrt{ }$ & $\neq \sqrt{ }$ & *Year I \\
\hline & & & & & & & Year 2 \\
\hline & & & & & & & Year 3 \\
\hline \multirow{3}{*}{6} & $\S \sqrt{ }$ & $\partial \sqrt{ }$ & $+\sqrt{ }$ & & & & *Year I \\
\hline & & & & & & & Year 2 \\
\hline & & & & & & & Year 3 \\
\hline
\end{tabular}




\begin{tabular}{|c|c|c|c|c|c|c|c|}
\hline \multirow{3}{*}{7} & $\S \sqrt{ }$ & $\partial \sqrt{ }$ & $+\sqrt{ }$ & & $\sqrt{ }$ & & *Year I \\
\hline & & & & $\sqrt{ }$ & & & Year 2 \\
\hline & & & & & & & Year 3 \\
\hline \multirow{3}{*}{8} & $\S \sqrt{ }$ & $\partial \sqrt{ }$ & $+\sqrt{ }$ & & $\sqrt{ }$ & & *Year I \\
\hline & & & & & & $\sqrt{ }$ & Year 2 \\
\hline & & & & $* * \sqrt{ }$ & & & Year 3 \\
\hline \multirow{3}{*}{9} & $\S \sqrt{ }$ & $\partial \sqrt{ }$ & $+\sqrt{ }$ & & $\sqrt{ }$ & $\sqrt{ }$ & *Year I \\
\hline & & & & & & & Year 2 \\
\hline & & & & & & & Year 3 \\
\hline \multirow{3}{*}{10} & $\sqrt{ }$ & & $\sqrt{ }$ & $\sqrt{ }$ & $\sqrt{ }$ & $\sqrt{ }$ & *Year I \\
\hline & & & & & & & Year 2 \\
\hline & & & & & & & Year 3 \\
\hline \multirow{3}{*}{11} & $\S \sqrt{ }$ & $\partial \sqrt{ }$ & $+\sqrt{ }$ & & & & *Year I \\
\hline & & & & & & & Year 2 \\
\hline & & & & & & & Year 3 \\
\hline \multirow{3}{*}{12} & $\S \sqrt{ }$ & $\partial \sqrt{ }$ & $+\sqrt{ }$ & & & & *Year I \\
\hline & & & & & & & Year 2 \\
\hline & & & & & & & Year 3 \\
\hline
\end{tabular}

Note: "Year 1 is the first academic year after the Freshman Year.

${ }^{\S}$ Combined with Physiology.

"Combined with Anatomy \& Physiology.

tCombined with Anatomy.

$\ddagger$ Given as Elective.

*Given as Pathology in Years 3 \& 4.

\section{Discussion and Conclusion}

Nursing curricula have been evolving over the years. Today's emphases on evidence-based practice, the learner and measurement of learning outcomes, integration, translational science and research, and the application of technology to the delivery of the program provide both challenges and opportunities for nurse educators. All these factors should be carefully considered by the nursing faculty and educators when examining the curriculum and considering changes. Today and tomorrow's curricula call for an integration of knowledge and processes that are learner- and consumer-based, leading to excellence in the quality of the program. This goes in parallel with the urgent and continuous need for research on nursing curriculum design, development, implementation and evaluation, pillars which ensure the application of evidence-based nursing (EBN) practice.

Learning is defined as a "change in behavior (knowledge, attitudes, and/or skills) that can be observed or measured and that occurs as a result of exposure to environmental stimuli" [19]. A learning theory is defined as a "coherent framework of integrated constructs and principles that describe, explain, or predict how people learn" [20]. Learning theories and concepts play a crucial role in the practice of health care and nursing education. In the real world of complex clinical sites and busy classrooms, educators draw from a variety of learning theories for the teaching strategies that are appropriate for a learner, course, content, and process. Moreover, nurse faculty should rely on a variety of approaches to learning due to diversity in learners [21]. Although each faculty has a favorite theoretical approach(s), many of them have the potential to contribute tactics to learning and teaching situations. Organization of content (cognitivism), role modeling (social cognitive), rewards and reinforcement (behaviorism), positive regard for students (humanism), and the unique perspective of the learner (constructivism) all have important benefits. Nurse faculty can custom strategies from several theoretical models at the same time.

Taxonomy denotes classification. Educational taxonomy provides a way for educators to develop, view, and evaluate learning objectives via a classification system. It is convenient for use at the course and curricular levels. Critical thinking is directly applicable to educational taxonomy, and taxonomy developers recognized the need to assess the reasoning and problem-solving abilities of students. The degree to which the student engages with the content lies at the hear of the development of critical thinking skills. This could best be attained using well-structured active learning strategies. Curriculum developers should consider the global context in which students both learn and grow their critical thinking skills. This is achieved by taking into consideration several factors, including program outline and the underlying philosophy, larger institution orientation, educators and learners, funds, global and local health care environments, the dynamic nature of society at large, and the community (a very important factor to consider). The key to success to consider these factors could be enhanced through the understanding of the "contextual" nature in which learning occurs. 
Knowledge is taxonomized into several categories. Factual knowledge pertains to the basics that students need to know to be acquainted with the discipline, such as knowledge of bones and muscles. Conceptual knowledge involves understanding the interrelationships of parts within a structure (relationships among bones, muscles, and nerves). Procedural knowledge includes knowing how to do something, such as knowledge of criteria for determining which procedure to use, proper steps in performing a procedure or developing algorithms/concept maps for patient-specific care (Which intravenous solution to use, how to start an intravenous line, which vein to puncture). Metacognitive knowledge is knowledge of cognition in general, as well as having a personal awareness and knowledge of cognition, such as strategic knowledge, knowledge about cognitive tasks within different contexts, and self-knowledge (e.g., applying multi-level knowledge and skills in critical care settings) [22].

We analyzed in this study the undergraduate nursing program offered at 12 various universities in Lebanon. Our results showed that basic science courses are still offered as separate entities, and horizontal and vertical integration of Anatomy, Embryology, Physiology, Pathophysiology, Biochemistry, and Microbiology is still lacking. One could argue that topics pertaining to such disciplines are revisited in the second- and third-year courses, such as medical-surgical nursing, critical care nursing, pediatric nursing, maternal nursing, recovery nursing, emergency nursing, operating room nursing, and geriatric nursing. However, such an approach could not be classified as proper vertical integration. The effort that the second and third year nursing students enrolled in a threeyear Bachelor of Science in Nursing degree program have to make to remember the basic concepts studied in the above-mentioned disciplines, and which result from knowledge gap and lack of correlation, should be a priority research that needs to be addressed in nursing schools across the globe. What we have observed in the undergraduate nursing curricula which we have studied applies to many similar nursing curricula around the world. We are in the process of conducting a regional and international comparative study for that matter.

We conclude by inviting nursing schools around the world to join our endeavor in researching models to be applied in nursing curricula, and which could help in minimizing knowledge gap and fostering correlation between basic and clinical components of the nursing degree programs. Such models include horizontal and vertical integration.

\section{References}

1. RG Berns, PM Erickson (2001) Contextual Teaching and Learning: Preparing Students for the New Economy 5: 1-8.

2. LS Vygotsky (1962) Thought and Language, Cambridge, MIT Press, USA
3. J Piaget as cited in MP Driscoll (2000) Psychology of Learning for Instruction, Needham Heights, Allyn \& Bacon, MA, USA.

4. RE Mayer (1999) Designing Instruction for Constructivist Learning in CM Reigeluth's, Instructional Design Theories and Models: A New Paradigm of Instructional Theory-Volume II. Lawrence Erlbaum Associates. Pub, New Jersey, USA.

5. AW Chickering, ZF Gamson (1999) Development and Adaptations of the Seven Principles for Good Practice in Undergraduate Education. John Wiley \& Sons Inc 1999(80): 75-81.

6. D Parnell (1999) Why do I Have to Learn This? Teaching the Way People Learn Best. CORD Communications, USA.

7. BA Lankard (1995) New Ways of Learning in the Workplace, Digest. ERIC Information Analysis Products 161(ED385778).

8. ZL Berge (2002) Active, Interactive, and Reflective eLearning, Quarterly Review of Distance Education. 3(2): 181-191.

9. E Jensen (1995) Brain-Based Learning, Turning Point, San Diego, CA.

10. (2006) Society for Neuroscience, Brain Facts: A Primer on the Brain and Nervous System.

11. E Jensen (1998) Teaching with the Brain in Mind, Association for Supervision and Curriculum Development, Alexandria, VA.

12. M Diamond (1988) Enriching Heredity: The Impact of Environment on the Anatomy of the Brain. New York, Free Press.

13. Blanchard (2001) Contextual Teaching and Learning, Educational Services.

14. RC Schank, TR Berman, KA Macpherson (1999) Learning by Doing, in C. M. Reigeluth's Instructional Design Theories and Models: A New Paradigm of Instructional Theory, Vol II. Lawrence Erlbaum Associates, New Jersey, USA, Pub 2: 172-180.

15. RJ Lenschow (1998) From Teaching to Learning: A Paradigm Shift in Engineering Education and Lifelong Learning. European Journal of Engineering Education 23(2): 155-162.

16. Van Kotze, L Cooper (2000) Exploring the Transformative Potential of Project-Based Learning in University Adult Education, Studies in the Education of Adults. 32(2): 212-229.

17. MM Bevevino, J Dengel, K Adams (1999) Constructivist Theory in the classroom. Clearing House 72(5).

18. (2014) Lebanese Higher Education Institutions, European Union Erasmus Plus Programme, National Erasmus Plus Office, Lebanon.

19. Bastable S, Alt M (2014) Overview of education in health care. In S Bastable (Edition), Nurse educator: Principles of teaching and learning for nursing practice ( $4^{\text {th }}$ edn,). Jones \& Bartlett, Burlington, MA, p. 3-30.

20. Braungart M, Braungart R, Gramet $P$ (2014) Applying learning theories to health care practice. In $\mathrm{S}$ Bastable (Edition), Nurse educator: Principles of teaching and learning for nursing practice $\left(4^{\text {th }}\right.$ edn, $)$. Jones \& Bartlett, Burlington, MA, pp. 63-110.

21. Hunt D (2013) The new nurse educator: Mastering academe. NY: Springer Publishing, New York, USA.

22. Krathwohl DR (2002) A revision of Bloom's taxonomy: An overview. Theory into Practice 41(4): 212-218. 